\section{Child and adolescent mental health services in Brazil: structure, use and challenges}

\section{Serviços de saúde mental para crianças e adolescentes no Brasil: estrutura, uso e desafios}

Vagner dos Santos 1

Anna Fernández 2

\begin{abstract}
Objectives: to examine the state of Child and Adolescent Mental Health (CAMH) services and to compare the availability and use of $C A M H$ services across the five regions of Brazil.

Methods: the Mental Health Matrix Model was used as a framework to describe the state of CAMH services. Documents and administrative datasets were consulted, covering the whole country and the five Brazilian regions as separate levels. This enabled cross-region comparisons and combination with the three temporal dimensions (Input, Process and Outcome).

Results: although there are national policies regulating $C A M H$, along with an integral protection doctrine, scarcity of services was unequally distributed across the regions. A number of trends relating to social development and mental health (e.g. intellectual disability treated prevalence) were also identified.

Conclusions: substantial advances in $C A M H$ policy characterize the contemporary Brazilian CAMH system, especially regarding the implementation of community based mental health services for children and adolescents. However, the data reveals great inequalities and geographic variation regarding social indicators, service structure and use.
\end{abstract}

Key words Child, Adolescent, Mental health, Mental health services

\author{
${ }^{1}$ University of Brasilia. Faculty of Ceilandia. QNN 14 Area Especial. \\ Ceilândia Sul. Brasília, DF, Brazil. CEP: 72.220-140. \\ E-mail: vagner@unb.br \\ 2 Fundació Sant Joan de Déu. Research and Development Unit, Sant \\ Joan de Déu - SSM. Barcelona, Spain.
}

\section{Resumo}

Objetivos: analisar a situação dos serviços de saúde mental para crianças $e$ adolescentes $e$ comparar a disponibilidade e uso dos mesmos entre as cinco macrorregiões do Brasil.

Métodos: utilizou-se o The Mental Health Matrix Model como marco referencial para descrever a situação dos serviços de saúde mental para crianças e adolescentes. Analisaram-se documentos e dados originais de bases administrativas do governo federal. Isso permitiu a comparação entre as regiões e em relação ao tempo (investimentos, processos e resultados).

Resultados: embora existam politicas e regulamentos nacionais sobre a saúde mental de crianças e adolescentes, alinhadas com a doutrina da proteção integral, verificou-se um insuficiente número de serviços com uma distribuição desigual entre as macrorregiões. Adicionalmente, foi possivel identificar tendências relacionadas ao desenvolvimento social e a saúde mental (ex. prevalência de atendimentos em deficiência intelectual)

Conclusões: avanços substanciais nas políticas caracterizam o sistema brasileiro de saúde mental para crianças e adolescentes principalmente no que se refere à implementação de serviços de base comunitária. No entanto, os dados mostram desigualdade e variações regionais dos indicadores sociais, de estrutura e uso dos serviços.

Palavras-chave Criança, Adolescente, Saúde mental, Serviços de saúde mental 


\section{Introduction}

There is a lack of services for children and adolescents (CAs) with mental health problems, especially in low- and middle-income countries. 1,2 In fact, the World Health Report indicates that one of the five priorities in mental health is to develop specific research in Policies and Services in the field. ${ }^{3}$ The need for Child and Adolescent Mental Health $(\mathrm{CAMH})$ services has been a subject of debate among Brazilian academics in recent decades, but with few practical consequences. One of the major challenges for adequate planning CA mental healthcare is the lack of information. In order to develop an evidence-based policy, it is crucial to know the prevalence and distribution of mental health problems in this population and what resources are already available. ${ }^{4}$ In Brazil, local studies indicate that the prevalence of CA mental health problems (not just specific disorders) oscillates between 7\% and $12.7 \%$. This range may be even wider if risk factors are included.5-7 Unfortunately, to the best of our knowledge, there is no data on the prevalence of CA mental health problems produced using standardized instruments for diagnosis of mental disorders and conducted in a representative Brazilian sample.

Other factors also influence the development and organization of mental health services. These include a) financial controls or political strategies; b) politics and consumer organizations and opinions; and c) the value of healthcare organizations. 8 The need for adequate care for those CAs suffering mental problems has been widely recognized, but it remains a public health challenge in Brazil. The first step to improve the care of CAs with mental health problems is to perform a comprehensive analysis of the situation. Cross-regional comparisons are thus useful for detecting shortcomings and inequities in access to treatment. This is crucial for ensuring equity in access and treatment, especially for CAs with mental illness. ${ }^{9}$

The Mental Health Matrix Model developed by Tansella and Thornicroft was used as a conceptual framework for analysis of the provision of CAMH in Brazil.10,11 This descriptive model is the one recommended by the World Health Organization. It monitors the mental health system in space and time, identifying priorities for improving the system. The aim of the present study is thus to examine the state of Child and Adolescent Mental Health (CAMH) services and to compare the availability and use of CAMH services across the five regions of Brazil.

\section{Methods}

The Mental Health Matrix Model was used as a framework for analysis of the CAMH system in Brazil. This model was developed for the assessment of mental healthcare services. It is organized into two dimensions: geographical and temporal. The geographical dimension is divided into three levels: 'Country/Regional', 'Local' and 'Patient'. The levels of the temporal dimension are Inputs, Process and Outcomes. ${ }^{11}$

\section{The Geographical dimension}

The country as a whole and the five Brazilian regions were considered as separate levels. This enabled cross-region comparisons and combination with the three temporal dimensions (Input, Process and Outcome). Information relating to the local and patient level was not included, since the aim was to explore the national structure and to compare the implementation of CAMH services within regions (Table 1).

\section{The Temporal Dimension}

I) Inputs: The 'Inputs Dimension' is divided into two categories: invisible and visible. The 'invisible inputs' are those elements that increase the effective functioning of the service network. They refer specifically to policies and regulations. A number of documents were consulted to identify current legal rights regarding CAs. The 'visible inputs' considered mainly concerned expenditure (outpatient care and hospital admission costs).

II) Process: The 'Process Dimension' is defined as those activities that are needed to deliver mental health services. This therefore refers to a wide range of clinical-related procedures that occur in a mental health service system, such as treatment guidelines, protocols, definition of target groups and data on service activity. A review of cross-sector documents was also included and prevalence was used as a proxy for the most significant mental problems.

III) Outcomes: the 'Outcomes Dimension' refers to the potential consequences of health services provision. When combined with the country and regional levels, it uses population-based indicators. Some examples of outcomes from adult-based mental health services research are: rate of suicide and homelessness; and the rate of people with mental disorders inappropriately imprisoned, who would be better treated in a mental health facilities. The present study used the following indicators as a 
Geographical and Temporal dimension to analyze child and adolescent mental health services. Brazil, 2009.

\begin{tabular}{|c|c|c|c|c|}
\hline & & \multicolumn{3}{|c|}{ Temporal dimension } \\
\hline & & Inputs & Process & Outcomes \\
\hline \multirow{8}{*}{ 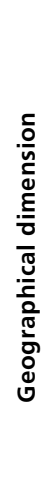 } & \multirow{8}{*}{ 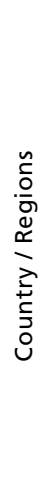 } & Policies and regulations & Targeting of special groups & Street children and adolescents \\
\hline & & CAPS-II $i$ coverage rate & Data from the system use & Socio-educational measures \\
\hline & & Expenditure & Hospital use & School dropout and failure \\
\hline & & Non-hospital & Out-Care use & Inappropriate Age/Grade \\
\hline & & Hospital & & Suicide rate \\
\hline & & & & Violent death \\
\hline & & & & alcohol \& tobacco - \\
\hline & & & & lifetime use/dependence \\
\hline
\end{tabular}

Adapted version of The Mental Health Matrix Model; CAPS= Community Psychosocial Centers.

\section{Table 2}

Sources used to collect information. Analysis of the child and adolescent mental health services. Brazil, 2009.

\begin{tabular}{|c|c|c|c|}
\hline \multicolumn{2}{|c|}{ Information collected } & \multirow{2}{*}{$\begin{array}{l}\text { Source } \\
\text { The Brazilian official legislation browser } \\
\text { (www4.planalto.gov.br/legislacao) }\end{array}$} & \multirow{2}{*}{$\frac{\text { Year }}{1989-2009}$} \\
\hline \multirow{9}{*}{ 节 } & Policies and regulations & & \\
\hline & CAPS-II $i$ coverage rate & CAPS-II $i:$ 'Mental Health on Data' (Saúde Mental em & 2009 \\
\hline & & Dados) & \\
\hline & & Population under 18 years: brazilian institute of & \\
\hline & & geography and statistics (Censo, 2009) & \\
\hline & & (rate: 1:100.000- total of CAPS-II $i /$ pop under 18 years old) & \\
\hline & Expenditure & $\begin{array}{l}\text { DATASUS: Ministry of Health's department responsible for } \\
\text { gathering data provided by health services }\end{array}$ & 2009 \\
\hline & Non-hospital & DATASUS: Out-care Information System (SIA/SUS) & 2009 \\
\hline & Hospital & DATASUS: Hospital Information System (SIH/SUS) & 2009 \\
\hline \multirow{4}{*}{ 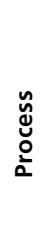 } & Targeting of special groups & Final Reports of the National Forum on Child and & $2004-2009$ \\
\hline & & Adolescent and Official Documents & \\
\hline & Hospital use information & DATASUS: Hospital Information System (SIH/SUS) & 2009 \\
\hline & Out-Care use information & DATASUS: Out-care Information System (SIA/SUS) & 2009 \\
\hline
\end{tabular}


Sources used to collect information. Analysis of the child and adolescent mental health services. Brazil, 2009.

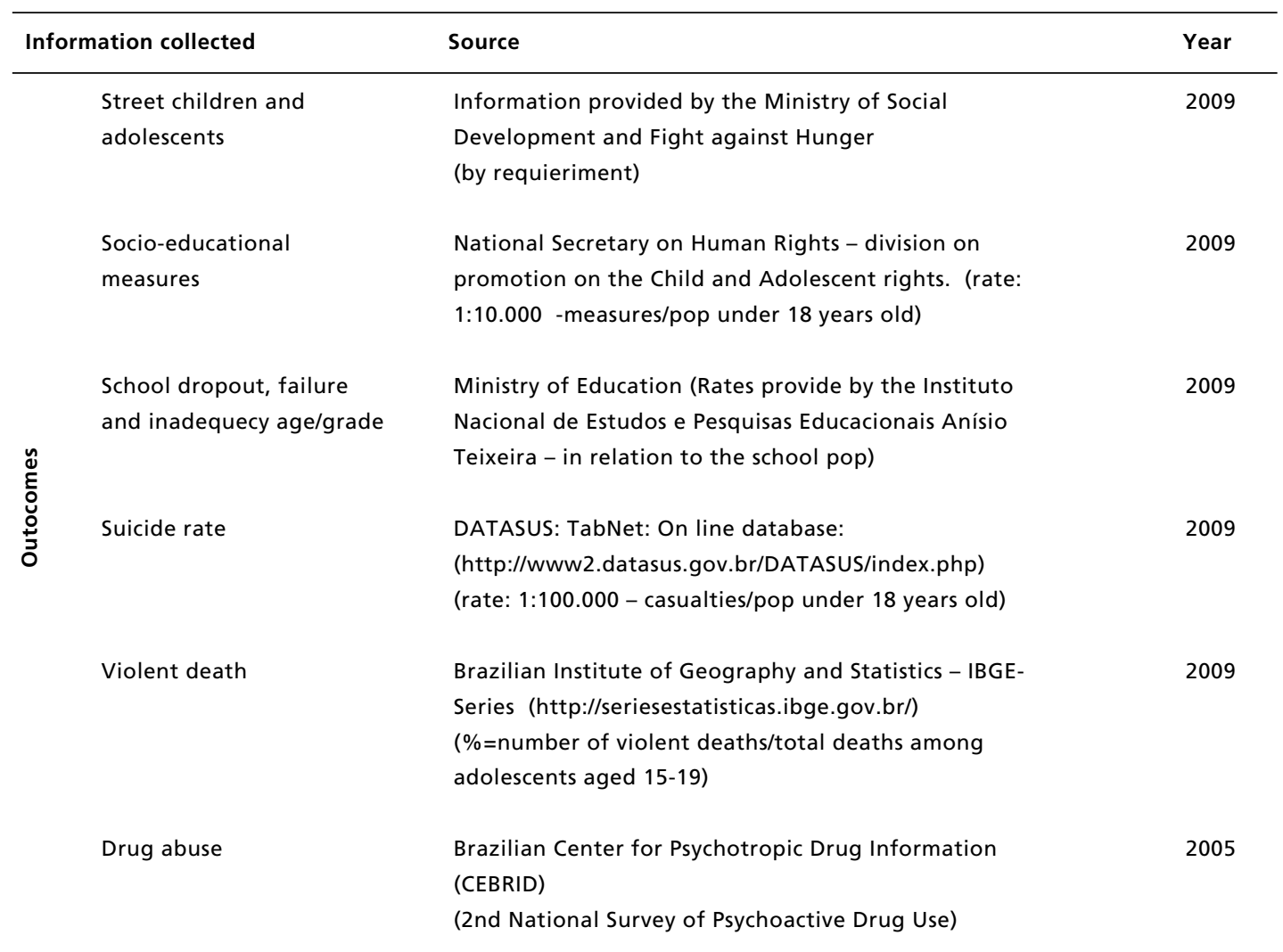

proxy for outcomes for CAs: a) the prevalence of children and adolescents living on the street; rate of young offenders (i.e. CAs in the justice/correctional system, rate of suicide; rate of violent death; and lifetime prevalence of alcohol and tobacco use and dependence.

Official documents and original data from national sources were used to provide an overview of CAMH input (i.e. structure), process (i.e. use) and outcomes (i.e. health and social indicators). Sources from the Ministry of Health, the Ministry of Education and the Ministry of Social Development and Fight against Hunger (MDS) were consulted to find information relating to the inputs and the process. The structure and use of outpatient and inpatient (i.e. hospital) care was also examined by consulting the National Health Database (DATASUS). The Ministry of Health department is responsible for gathering this data from the health services. Data from January to December 2009 were selected. Data from the Outpatient care Information System (SIA/SUS) and the Hospital Information
System (SIH/SUS) were also collected. The International Statistical Classification of Diseases and Related Health Problems was used to restrict the study to codes related to mental health (i.e. from F00 to F-99). Data was restricted to Children and Adolescents (i.e. those aged up to 18 years). The data was collected at the DATASUS Department in Porto Alegre. Local staff were consulted in case of doubts. Data from the Brazilian Institute of Geography and Statistics (IBGE) and the Brazilian Center for Psychotropic Drug Information (CEBRID) was also analyzed (Table 2). The year 2009 was taken as the year of reference for the whole analysis. However, the study that provided data on lifetime prevalence of alcohol and tobacco use and dependence was developed in 2005. The CEBRID defines as a "dependent" someone who has experienced at least three of the following six criteria: loss of control; reduced social/family involvement; tolerance; continued use of drug despite harm; attempts to cut down; or salience, for at least one month during the past year. 12 


\section{Results}

Common elements at the National level: Invisible Inputs (Policies and regulations) and Process (National Forum on CA Mental Health)

The reform of the Brazilian health sector began in the late 1980's, coinciding with the restoration of democracy. Health professionals, social movements and civil organizations participated in this process. Since 1988, a dynamic and complex health system, the Unified Health System -SUS (Law 8.080/90 and $8.142 / 90$ ) has been built up based on the principles of health as a citizen's right and as a duty of the State. The rights of CAs were guaranteed by the 'Children and Adolescents Statute' (ECA), in 1990 (Law 8.069/90), the first law specifically designed for this sector of the population, introducing the doctrine of integral protection. According to this law, the family, the community, society and the public authorities must ensure, by all means, the effective implementation of the rights to life, health, nutrition, education, sports, leisure, vocational training, culture, dignity, respect, freedom and family and community living. Specific reference is made to the health of children and adolescents. It also stipulates that all children and adolescents with disabilities must receive special treatment. However, it was a general statement and did not establish clear guidelines.

In the field of mental health, in 1989 a bill (PL $3.657 / 89$ ) proposing the elimination of asylums and the introduction of a community model for mental healthcare was sent to the chamber of deputies. This bill would remain stalled for 12 years. In 2001, the senate approved another proposal containing a similar approach. The Psychiatric Reform Law (Law $10.216 / 01$ ) stipulated the need for integrated care, as well as equitable and universal mental healthcare, in accordance with the 'Caracas Declaration'.13 However, the Psychiatric Reform Law did not address the specific category of CA mental health. The former was recognized in 2002, in the final report of the 3rd National Conference of Mental Health. This document presented 18 proposals regarding $\mathrm{CAMH}$, which were aligned with the SUS, the psychiatric reform law and the ECA. It stated that children and adolescents with mental health problems should be exclusively admitted to the pediatric ward of general hospitals (not psychiatric hospitals). It also emphasized the need for specialized community-based CAMH services.

The Brazilian Ministry of Health supported the Psychiatric Reform Law project and initiated the progressive replacement of psychiatric beds with community care. The substitute services, called Community Psychosocial Centers (CAPS) were classified according to three degrees of complexity. The implementation process started in 2002. Technical information regarding the functioning and financing of the CAPS and their classifications was established by Congress (GM/MS 336/02 and SAS/MS 189/02). The CAPS were classified as I, II and III, based on size, complexity and scope of the population. A multidisciplinary staff was established for each service (Table 3 ).

CAPS-II $i$ (CAPS Infant) aims specifically to provide mental healthcare for CAs, as well as for young people (aged up to 24 years old). The CAPSII $i$ multidisciplinary staff includes at least one Child and Adolescent psychiatrist (or a Pediatrician or Neurologist with formal education in mental health); one nurse; four other university graduate professionals (psychologist, occupational therapist, social workers) according to local needs; and five other professionals (high school level) to provide therapeutic and administrative support services. The CAPS-II $i$ is also responsible for organizing the CA mental healthcare network in its territory (a population of no more than 200,000).

In 2005, the Ministry of Health published "Ways Forward for Child and Adolescent Mental Health Policy" (Caminhos para uma politica de saúde mental infanto-juvenil). 14 This document recognized the historical inefficiency of the public health agenda to provide adequate care for this population. The main aim of this document was to provide an historical framework and to generate a discussion to consolidate national policy. The document also introduced the National Forum on CAMH created a year earlier by P GM 1.608/04. The National Forum on CAMH aims to articulate and promote intersector discussion of policy by engaging key stakeholders. It also aimed to establish national policy guidelines; to promote integration; coordination and communication among the various institutions working in the field; and to produce knowledge and information that supports the development of the system. As part of its work, the Forum recognized vulnerable groups that needed special attention. The deinstitutionalization of those living far from the family and community (due to problems with the criminal justice system or psychiatric disorders) was the main theme of the first recommendation. Following this tendency to integrate mental health with other sectors, the second recommendation pointed to the need for more effective cooperation on the part of institutions 
Table 3

Types of Community Psychosocial Centers. Brazil, 2009.

\begin{tabular}{|c|c|c|c|c|}
\hline Type & Scope of population & Work schedule & Days & Population target \\
\hline CAPS -I & $\begin{array}{l}\text { from } 20,000 \text { up to } \\
70,000 \text { inhab. }\end{array}$ & $8 a m-6 p m$ & Monday to Friday & adults \\
\hline CAPS-II & $\begin{array}{l}\text { from } 70,000 \text { up to } \\
200,000 \text { inhab. }\end{array}$ & 8 am - 6 pm (Extendible until 9 pm) & Monday to Friday & adults \\
\hline CAPS-II $i$ & over 200,000 inhab. & 8 am - 6 pm (Extendible until 9 pm) & Monday to Friday & $\begin{array}{l}\text { Child and } \\
\text { adolescent }\end{array}$ \\
\hline CAPS-II AD & over 100,000 inhab. & 8 am - 6 pm (Extendible until 9 pm) & Monday to Friday & $\begin{array}{l}\text { people with } \\
\text { alcohol and drug } \\
\text { consumption } \\
\text { problems }\end{array}$ \\
\hline CAPS-III & over 200,000 inha & 24 hours & $24 / 7,365$ days a year & adults \\
\hline
\end{tabular}

responsible for CAs. The third document acknowledged the lack of scientific knowledge regarding $\mathrm{CAMH}$ and the need for this information to establish specific target groups. This document also presented an experimental proposal program for CAs in partnership with a social-movement, conducted in Rio de Janeiro (in the southeast region of Brazil). Finally, it suggested the creation of a workgroup to assess the implementation of CAPS-II $i$. The 'Brasilia Declaration' highlighted several factors that need be taken into account at national level, such as the need for implementation of CAPSII $i$ in cities with more than 100,000 inhabitants, thereby broadening the scope of community-based CAMH services.

\section{Visible Inputs - Comparisons between regions}

In 2009, the total number of CAPS-II $i$ available in Brazil was 105 . However, these were unequally distributed, ranging from two services in the north to 46 in the southeast. The difference in this absolute number remained when the coverage rate was calculated. The national coverage rate of CAPS-II $i$ was 0.17 . The Southern region presented the best results, around 0.30 , whilst the northern region presenting the lowest coverage rate, ten times lower. This region, comprising seven states, was covered by only two CAPS-II $i$. Annual expenditure on CA outpatient and inpatient care in 2009 was around 46 million Brazilian reais (approximately 21 million USD). The northeast region accounted for $40.5 \%$ of the entire budget, followed by the southeast (32.3\%); and the southern (19.04\%) regions. Nevertheless, the southern region spent more resources than the northern region, which ranked lower for all categories, in absolute and relative numbers. All regions devoted more resources to outpatient than to inpatient care. The northeast region concentrated most resources on outpatient care. The mid-west followed by the southern region spent less on outpatient care, $67.6 \%$ and $73.7 \%$ respectively.

\section{Process}

Data relating to service use reveals the patterns of care. Treatment prevalence can be regarded as a proxy for the most significant problems in each region. The total number of inpatient admissions in 2009 was 13,510 . The southeast region accounted for almost $40 \%$ of the whole number, and the southern region had the highest relative number of admissions: 0.46. The main reasons for these admissions at national level were 1) disorders associated with alcohol and substance abuse (F10$19)$, and 2) acute cases of schizophrenia and other psychotic conditions (F20-29). These two groups together accounted for more that seventy per cent of the total. This profile was strongly influenced by the southern and mid-west regions, where a large number of admissions were attributed to drug abuse. By contrast, in outpatient care services, drug abuse had relative low presence, with schizophrenia and other acute psychotic conditions (F20-29) being the 
Distribution of inputs, process and outcome indicators for child and adolescent mental health services. Brazil, 2009.

\begin{tabular}{|c|c|c|c|c|c|c|}
\hline \multirow[b]{3}{*}{ Population under 18 years } & \multirow{2}{*}{ Brazil } & \multicolumn{5}{|c|}{ Regions } \\
\hline & & North & Northeast & Southeast & South & Central-West \\
\hline & $62,494(32 . \%) *$ & $6,209(9.9 \%) * *$ & $19,368(31 \%) * *$ & $24,067(38.5 \%) * *$ & $8,241(13.2 \%) * *$ & $4,613(7.4 \%)^{* *}$ \\
\hline \multicolumn{7}{|l|}{ INPUTS } \\
\hline \multicolumn{7}{|c|}{ al Protection Doctrine; Universal Healthcare System; Psychiatric Reform and the Forum Recommendation } \\
\hline CAPS-II $i(n)$ & 105 & 2 & 27 & 46 & 25 & 5 \\
\hline CAPS-II $i$ coverage ratea & 0.17 & 0.03 & 0.14 & 0.19 & 0.30 & 0.11 \\
\hline Total Expenditureb & $45,798,836.4$ & $1,080,137.66$ & $18,513,861.01$ & $14,791,661.55$ & $8,720,239.9$ & $2,692,936.26$ \\
\hline$\%$ & - & 2.36 & 40.42 & 32.30 & 19.04 & 5.88 \\
\hline \$/Pop under 18 years & 0.73 & 0.17 & 0.96 & 0.61 & 1.06 & 0.58 \\
\hline Outpatients & $37,502,501.38$ & $895,989.97$ & $16,779,682.37$ & $11,571,273.08$ & $6,434,844.86$ & $1,820,711.51$ \\
\hline$\%$ & 81.9 & 82.9 & 90 & 78.2 & 73.7 & 67.6 \\
\hline Hospital & $8,296,334.59$ & $184,147.69$ & $1,734,178.64$ & $3,220,388.47$ & $2,285,395.04$ & $872,224.75$ \\
\hline$\%$ & 18.1 & 17.1 & 10 & 21.8 & 26.3 & 32.4 \\
\hline PROCESS & & & & & & \\
\hline
\end{tabular}

Targeted groups CA living under some process of institutionalization, such as shelter, reformatory, psychiatric institutions, and so forth Hospital Use $(\mathrm{SIH})_{\infty}$

\begin{tabular}{|c|c|c|c|c|c|c|}
\hline Admissions (n) & 13,510 & $361(2.7 \%)$ & $2,531(18.7 \%)$ & $5,402(39.9 \%)$ & $3,813(28.2 \%)$ & $1,403(10.4 \%)$ \\
\hline Relative number admission & 0,21 & 0.06 & 0.13 & 0.22 & 0.46 & 0.30 \\
\hline \multicolumn{7}{|l|}{ Diagnosis registered (\%) } \\
\hline Organic mental disorders & 6.0 & 11.8 & 4.94 & 7.90 & 3.96 & 5.63 \\
\hline Substance Abuse & 40.91 & 9.97 & 27.02 & 34.19 & 59.98 & 47.97 \\
\hline Schizophrenia. Acute psycho, & 29.41 & 46.81 & 51.80 & 27.45 & 15.71 & 29.29 \\
\hline Mood [affective] disorders & 11.13 & 17.73 & 6.40 & 11.18 & 13.64 & 10.91 \\
\hline Neurotic. somatoform & 1.6 & 3.32 & 0.79 & 1.83 & 1.55 & 1.85 \\
\hline \multicolumn{7}{|l|}{ lisorders } \\
\hline Behavioral syndromes & 1.2 & . & 0.79 & 1.87 & 1.0 & 0.21 \\
\hline Disorders of adult personality & 1.74 & 1.11 & 1.15 & 2.94 & 1.05 & 0.21 \\
\hline Intellectual disability & 6.5 & 8.59 & 6.80 & 10.44 & 2.12 & 2.14 \\
\hline Dis, of psychological & 0.67 & 0.83 & 0.24 & 0.94 & 0.42 & 1.07 \\
\hline \multicolumn{7}{|l|}{ levelopment } \\
\hline CA Behavioral and emotion & 0.24 & 0.28 & 0.04 & 0.46 & 0.05 & 0.29 \\
\hline \multicolumn{7}{|l|}{ lisor, } \\
\hline Unspecified mental disorder & 0.52 & 0.28 & 0.04 & 0.78 & 0.52 & 0.43 \\
\hline
\end{tabular}


Distribution of inputs, process and outcome indicators for child and adolescent mental health services. Brazil, 2009.

\begin{tabular}{|c|c|c|c|c|c|c|}
\hline \multirow[b]{3}{*}{ Population under 18 years } & \multirow{2}{*}{ Brazil } & \multicolumn{5}{|c|}{ Regions } \\
\hline & & North & Northeast & Southeast & South & Central-West \\
\hline & $62,494(32 . \%)^{*}$ & $6,209(9.9 \%)^{* *}$ & $19,368(31 \%)^{* *}$ & $24,067(38.5 \%)^{* *}$ & $8,241(13.2 \%)^{* *}$ & $4,613(7.4 \%)^{* *}$ \\
\hline PROCESS & & & & & & \\
\hline
\end{tabular}

Targeted groups CA living under some process of institutionalization, such as shelter, reformatory, psychiatric institutions, and so forth

Outpatients Use $(S I A) \infty$

Outpatients $(n)$

$6,556,003 \quad 137,235(2.1 \%) \quad 1,691,814(25.8 \%) \quad 3,409,944(52.1 \%) \quad 1,028,087(15.6 \%) \quad 288,953(4.41 \%)$

Diagnosis registered (\%)

Organic mental disorders

Substance Abuse

Schizophrenia. Acute psycho,

Mood [affective] disorders

Neurotic. somatoform disorders

Behavioral syndromes

Disorders of adult personality

Intellectual disability

$\begin{array}{ccc}0.39 & 1.88 & 0.91 \\ 2.15 & 2.55 & 2.29 \\ 80.43 & 79.48 & 64.24 \\ 2.29 & 7.86 & 3.10 \\ 2.36 & 2.51 & 4.32 \\ 0.30 & 0.16 & 0.78 \\ 0.12 & 0.22 & 0.22 \\ 3.35 & 3.42 & 9.60 \\ 4.13 & 0.30 & 6.19 \\ 3.86 & 1.63 & \\ 0.61 & & 7.32 \\ & 0 & 1.02\end{array}$

0.11
1.07
90.81
0.80
0.96
0.05
0.04
0.83
3.44

0.23

0.53

Dis, of psychological

development

CA Behavioral and emotion

disorders

Unspecified mental disorder

$0.61 \quad 0$

1.02

1.55

5.36

2.57

83.13

72.04

2.14

5.24

2.12

3.89

0.30

0.44

0.22

1.86

0.11

1.88

$4.04 \quad 2.30$

\begin{tabular}{|c|c|c|c|c|c|c|}
\hline \multicolumn{7}{|l|}{ OUTCOMES } \\
\hline Socio-Educational Measure $\approx$ & 2.71 & 1.75 & 1.88 & 3.51 & 3.51 & 2.82 \\
\hline Admission & 1.9 & 1.19 & 1.25 & 2.56 & 2.08 & 1.88 \\
\hline Provisional admission & 0.56 & 0.38 & 0.46 & 0.61 & 0.66 & 0.74 \\
\hline Conditional parole & 0.25 & 0.19 & 0.17 & 0.34 & 0.27 & 0.2 \\
\hline
\end{tabular}

School $\Sigma$

\begin{tabular}{|c|c|c|c|c|c|c|}
\hline Dropout rate $(E)$ & 3.7 & 6.2 & 6.2 & 1.7 & 1.6 & 3.1 \\
\hline Dropout rate $(\mathrm{H})$ & 11.5 & 16.4 & 16.4 & 7.4 & 9.2 & 12 \\
\hline School failure (E) & 11.1 & 13.5 & 13.8 & 8.7 & 10.9 & 9.5 \\
\hline School failure $(\mathrm{H})$ & 12.6 & 10.6 & 9.3 & 14.8 & 14.1 & 13.9 \\
\hline Inappropriate Grade/Age (E) & 23.3 & 33.2 & 31.6 & 15.9 & 17.9 & 21.6 \\
\hline Inappropriate Grade/Age $(\mathrm{H})$ & 34.4 & 48.5 & 45.1 & 26.4 & 25.9 & 33.9 \\
\hline uicide rate $\approx$ & 1.03 & 1.36 & 0.88 & 0.62 & 0.62 & 1.97 \\
\hline iolent death $(\%)^{\ddagger}$ & 60. & 46.97 & 57.18 & 73.29 & 73.29 & 61.34 \\
\hline \multicolumn{7}{|l|}{ Icohol \& Tobacco *** } \\
\hline Lifetime prevalence of alcohol & 54.3 & 25.5 & 43.6 & 60.8 & 58.8 & 55 \\
\hline Dependence alcohol & 7 & 2.9 & 6.5 & 6.3 & 6.5 & 7.7 \\
\hline Lifetime prevalence of & 15.2 & 17.9 & 9.6 & 15.3 & 21.3 & 18.4 \\
\hline \multicolumn{7}{|l|}{ obacco use } \\
\hline Dependence tobacco & 2.9 & 5.5 & 0.5 & 3.3 & 3.6 & 2.5 \\
\hline
\end{tabular}

Source: Own elaboration with data from a variety of sources: see Table 03 ; $\%$ relative to the total population-in million; ** $\%$ relative to the total populate under 18 years old-in millon; aCalculated based on the availability of CAPS II -i and the population under 18 years old; bTotal expenditure in Brazilian Real, in 2009; Number of admission/Pop. Under 18years*1.000; $\propto$ Relative to the attribute cause of attention in the year of 2009 according with ICD-10; (E)Elementary School; (H)High School; $\Sigma$ Rates provided by the Ministry of Education; $\approx$ Rate$1: 100.000 ;$; \% based on the total death of the population aged 15-19 years; ${ }^{* *}$ Based on the population aged 12-17 years. 
main reason for care $(80.43 \%)$. These conditions $90.81 \%$ of the treatment prevalence in outpatient care settings in the southeast region, whilst only $64.24 \%$ of the northeast patients consulted health services for this problem. The second most frequent condition in the northeast region $(9.60 \%)$ was Intellectual Disabilities (F70-79). This dramatically differed from the southern region, where only $0.83 \%$ of the cases were diagnosed as falling into this category (Table 4).

\section{Outcomes}

Unfortunately, no national data is available on the prevalence of CAs living on the streets. The southeast and south regions had higher rates of young offenders in contact with the juvenile justice/correctional system than the national average, contrasting with the low rate in the north region. In all regions, incarceration at juvenile institutions was the judicial measure most often utilized.

Data from the Ministry of Education also highlighted differences between regions. The north and northeast regions had the worst indicators in almost all categories regarding school activities. The dropout rate at the elementary school level in these regions was three times higher than in the southeast and south. School failure had more unequal rates, distributed among regions and level of education. Furthermore, the inappropriate age for grade in high school level in the north and northeast regions was almost twice that of other regions.

Information regarding violent death among CAs showed this was a common problem. In fact, it represented the main cause of mortality in this group. The southeast region had the highest prevalence in this category. There was no substantial difference is suicide rate, although the mid-west region showed a slightly higher rate than the others.

The lifetime prevalence of alcohol use among adolescents aged 12-17 years was higher in the south and southeast regions. In spite of this, the centralwest region presented more cases of alcohol dependence among this population. In relation to lifetime prevalence of tobacco use, the southern region had the highest use-related indicator, whilst the northern region ranked first for tobacco dependence (Table 4).

\section{Discussion}

As has been shown elsewhere, we found that CA mental healthcare has been recently included in the Brazilian public health agenda.10,14,15 Although this new mental health system has gained legal and political support, the country still lacks a clear strategy for implementing policies regarding CA mental healthcare, with priorities and targets set at all levels. The challenge concerns how to implement the national policies while taking into account the different needs of the regions. This includes a change in the treatment of young people with alcohol and substance use problems, who are currently mainly treated in hospital.

As shown by other studies, ${ }^{1,16}$ we found that the provision of services for CAs with mental problems was poor. The availability of CAPS-II $i$ was clearly insufficient and unequally distributed. A previous study, which mapped the Brazilian resources for CA mental healthcare in 2007, found a much higher coverage rate of CAMH services $(1.08 / 100,000)$ than the present study. 15 However, this study included all categories of CAPS, even those that did not attend CAs. Although we recognize that there has been a great improvement in the provision of outpatient mental healthcare, we have only included those services specially designed for CAMH care. Not to take this into account and to merge services providing care for CAs with services for adults would lead to inaccurate data analysis. We therefore decided to include only the CAPS-II $i$ category to calculate the coverage rate.

The coverage rate has grown since 2009. According to the National Coordination of Mental Health report published in 2012,17 the national number of CAMH services has risen to 149 (from $105)$. The south has achieved a coverage rate of 0.38 , while, in the northern region, ten years after the psychiatric reform, CAPS-II $i$ coverage (0.05) was a lowest and remained unchanged. Poor areas face a double disadvantage in relation to mental health provision, since they spend a smaller proportion of their already scarce resources on mental health.18 Other studies addressing health issues in Brazil have also found an unequal distribution of services among Brazilian regions. ${ }^{19,20}$ In recent decades, political and social changes have tried to reduce these inequalities between wealthy (south and southeast) and poor (north and northeast) regions. ${ }^{21}$ This is important because socioeconomic deprivation has been shown to be both a cause (i.e. social causation hypothesis) and a result (i.e. social selection hypothesis) of mental illness. ${ }^{22}$ Nevertheless, we have identified some trends relating to social development and mental health.

In the case of intellectual disability, the northeast exhibited a higher prevalence, which may indicate structural problems within the region (with maternal 
health; women's education; or child nutrition).20,21 These assumptions are also supported by school data, as this region has the lowest indicators. By contrast, school data in the south showed a different profile. As indicated in the literature on education, non-attendance, failure and dropping-out of school may be a marker for childhood adversity, increasing the risk of mental illness. ${ }^{23}$ The data collected by the present study thus highlights the different needs of different regions.

The main challenge that faces Brazil concerns the provision of mental health resources, including CAPS-II $i$. The task of scaling up the number of facilities and other resources to provide adequate $\mathrm{CA}$ mental healthcare remains undone. This is a complex challenge that requires inter-sector collaboration to fully comply with the principle of holistic and integrated care. The implementation of CAPS-II $i$ may be considered the key element missing in this process. CAPS-II $i$ are responsible for integrating the different sectors and providing consultation and supervision in the territory they cover. They also act as liaison services. The use of non-clinical settings, such as schools and community services are suggested as accessible ways to promote mental health.1,24 The lack of CAPS-II $i$ may thus be regarded as a proxy for a fragmented system, which also neglects the importance of having specific and integrated CAMH services. There is good evidence that it is preferable to treat children and adolescents in the least restrictive environment and as close to their communities as possible.1,10 In fact, admission to psychiatric hospitals and 'reformatories' is associated with a lack of ability to respond to mental heath related problems.

Stigma and discrimination are important factors in the reluctance of many people to seek help or even accept mental problems. ${ }^{25}$ One study regarding $\mathrm{CAMH}$ in Italy found a significant reduction in access to treatment when CAs received care in the same facilities as adults, since was associated with stigma. 26 Thus, placing CAPS-II $i$ at the center of CAMH care, could help remove the stigma and reduce the institutionalization of children and adolescents, representing a step forward in the care of children and adolescents with mental health pro- blems.

We should acknowledge a number of limitations of the present study. First, it does not consider some important inputs such as other services that also treat CAs with mental health problems (i.e. primary care, social and educational services) or the availability and skills of staff (i.e. distribution of Full-Time Equivalent Staff). Second, it was not possible to link the different inputs and processes with the outputs, owing to the limited quality of available data. Third, the analyses of coverage rate should be adjusted by two factors: a) accessibility and b) the populationbased prevalence of mental health problems. This will allow us to assess the adequacy of resources. Fourth, the present study excluded analysis of local and patient dimensions from the Mental Health Matrix Model because of limited access to this data.

In spite of these limitations, this is the first time that Brazilian CAMH care has been analyzed using a validated tool, such as the Mental Health Matrix Model. This is an innovative study that sheds new light on the debate. The results found in this study and future analysis using the Mental Health Matrix Model will be crucial for monitoring the impact of national polices and actions regarding child and adolescent mental healthcare.

In conclusion, the contemporary Brazilian CAMH system is characterized by advances in CAMH policy, but also by large geographical variations in service use and social indicators. Inter-sector action is imperative if integrated care is to be ensured. Education and poverty are two critical aspects to be considered in CAMH planning both at regional and national level. Adequate implementation of CAPS-II $i$ is a key element of this process.

\section{Acknowledgements}

We would like to thank the DATASUS staff in Porto Alegre city for their assistance with data collection; Professor Sam Willner (Linköping Unviversity) for his insights and supervision; Sara Leon Spesny and Carolina Chassot for their comments on the final draft of this paper. VS would also like to acknowledge financial support from the IFP-Ford Foundation.

\section{References}

1. Patel V, Flisher AJ, Hetrick S, McGorry P. Mental health of young people: a global public-health challenge. Lancet. 2007; 369 (9569): 1302-13
2. Patel V, Kleinman A. Poverty and common mental disorders in developing countries. Bull World Health Organ. 2003; 81 (8): 609-15. 
3. WHO (World Health Organization). The World Health Report 2001. Mental Health: New Understanding, New Hope. Geneva; 2001.

4. Rohde LA. The need of epidemiological data on child mental disorders from low-middle income countries. Eur Child Adolesc Psychiatry. 2011; 20 (10): 497-8.

5. Goodman R, Neves dos Santos D, Robatto Nunes AP, Pereira de Miranda D, Fleitlich-Bilyk B, Almeida Filho N. The Ilha de Maré study: a survey of child mental health problems in a predominantly African-Brazilian rural community. Soc Psychiatry Psychiatr Epidemiol. 2005; 40 (1): 11-7.

6. Fleitlich-Bilyk B, Goodman R. Prevalence of child and adolescent psychiatric disorders in southeast Brazil. J Am Acad Child Adolesc Psychiatry. 2004; 43 (6): 727-34.

7. Anselmi L, Fleitlich-Bilyk B, Menezes AMB, Araújo CL, Rohde LA. Prevalence of psychiatric disorders in a Brazilian birth cohort of 11-year-olds. Soc Psychiatry Psychiatr Epidemiol. 2009; 45 (1): 135-42.

8. Fernández A, Pinto-Meza A, Serrano-Blanco A, Alonso J, Haro JM. An Introduction to Mental Health Services Research. In: Tsuang MT, Tohen M, Jones PB, editors. Textbook in Psychiatric Epidemiology. 3 ed. Chichester, UK: John Wiley \& Sons, Ltd; 2011. p. 133-54.

9. Sturm R, Ringel JS, Andreyeva T. Geographic disparities in children's mental health care. Pediatrics. 2003; 112 (4): e308.

10. WHO (World Health Organization). Child and Adolescent Mental Health Policies and Plans. Geneva; 2005 .

11. Thornicroft G, Tansella M. The Mental Health Matrix: A Manual to Improve Services. 1 ed. Cambridge, UK: Cambridge University Press; 2006.

12. CEBRID. II Levantamento Domiciliar sobre o Uso de Drogas Psicotrópicas no Brasil: 2005. Secretaria Nacional Antidrogas. Brasília, DF; 2007.

13. WHO (World Health Organization). Report on Mental Health System in Brazil, World Health Organization \& Brazilian Ministry of Health, Brasília, DF, Brazil; 2007.

14. Brasil. Ministério da Saúde. Caminhos para uma Política de Saúde Mental Infanto-Juvenil. Brasília, DF; 2005.

15. Couto MCV, Duarte CS, Delgado PGG. Child mental health and Public Health in Brazil: current situation and challenges. Rev Bras Psiquiatr. 2008; 30: 384-9.
16. Lund C, Boyce G, Flisher AJ, Kafaar Z, Dawes A. Scaling up child and adolescent mental health services in South Africa: human resource requirements and costs. J Child Psychol Psychiatry. 2009; 50 (9): 1121-30.

17. Brasil. Ministério da Saúde. Saúde Mental em Dados 10. Coordenação Geral de Saúde Mental, Álcool e Outras Drogas; Brasília, DF; 2012

18. Saxena S, Thornicroft G, Knapp M, Whiteford $H$. Resources for mental health: scarcity, inequity, and inefficiency. Lancet. 2007; 370 (9590): 878-89.

19. Travassos C, Viacava F, Fernandes C, Almeida CM. Social and geographical inequalities in health services utilization in Brazil. Ciênc Saúde Coletiva. 2000; 5 (1): 133-49.

20. Paim J, Travassos C, Almeida C, Bahia L, Macinko J. The Brazilian health system: history, advances, and challenges. Lancet. 2011; 377 (9779): 1778-97.

21. Victora CG, Aquino EML, Leal MC, Monteiro CA, Barros FC, Szwarcwald CL. Maternal and child health in Brazil: progress and challenges. Lancet. 2011; 377 (9780): 186376

22. Reiss F. Socioeconomic inequalities and mental health problems in children and adolescents: A systematic review. Soc Sci Med. 2013; 90: 24-31.

23. Goodman A, Fleitlich-Bilyk B, Patel V, Goodman R. Child, Family, School and community risk factors for poor mental health in Brazilian schoolchildren. J Am Acad Child Adolesc Psychiatry. 2007; 46 (4): 448-56.

24. Kleintjes S, Lund C, Flisher AJ. A situational analysis of child and adolescent mental health services in Ghana, Uganda, South Africa and Zambia. Afr J Psychiatry. 2010; 13 (2): 132-9.

25. Heflinger CA, Hinshaw SP. Stigma in child and adolescent mental health services research: understanding professional and institutional stigmatization of youth with mental health problems and their families. Adm Policy Ment Health. 2010; 37 (1-2): 61-70.

26. Pedrini L, Colasurdo G, Costa S, Fabiani M, Ferraresi L, Franzoni E, Masina F, Moschen R, Neviani V, Palazzi S, Parisi R, Parmeggiani A, Preti A, Ricciutello C, Rocchi MBL, Sisti D, Squarcia A, Trebbi S, Turchetti D, Visconti P, Tullini A, Girolamo G, PREMIA Group. The characteristics and activities of child and adolescent mental health services in Italy: a regional survey. BMC Psychiatry. 2012; 12 (1): 7 .

Recebido em 11 de fevereiro de 2014

Versão final apresentada em 27 de maio de 2014

Aprovado em 30 de junho de 2014 